\title{
MORPHOMETRIC STUDY OF THE MENINGEAL SHEATH OF THE OCULO MOTOR NERVE IN THE LATERO-SELLAR LODGE: neuro surgical interest
}

\section{Fréjus Séry, Rodrigue Koffi}

Laboratory of anatomy, Bouaké Alassane OUATTARA University, Graduate school of Medecine Bouaké Côte d'Ivoire. 01 BPV 18 Bouaké 01/Côte d'Ivoire. Frejussery05@gmail.com

\begin{abstract}
The meningeal sheath of the oculomotor nerve is also known that the latero-sellar lodge. It has both dural and extra-dural components. This sheath contains vascular elements including the carotid and nervous siphon, the motor nerves of the eye to which are added the division branches V1 and V2 of the trigeminal nerve. The oculomotor nerve runs through this lodge wrapped in its meningeal sheath. The purpose of this study was to document the dimensions of the different segments of the nerve as it crosses the lodge. Eight pairs of lodges were the subject of this study. Dead bodies fixed with $10 \%$ formalin for two to three weeks underwent a craniotomy. After removal of the brain, nerve III and its meningeal envelope were dissected and exposed. The different segments of the nerve were measured in both sides. The entrance orifice of the porus of the oculomotor nerve III was located behind the anterior clinoid process to $7.2 \mathrm{~mm}$ (extreme from 3 to $13 \mathrm{~mm}$ ) on the right and to $7.40 \mathrm{~mm}$ (extreme from 4 to 12) on the left. The meningeal cul-de-sac represented the intra-conical segment and was either $5.2 \mathrm{~mm}$ long (extreme from 4 to $6.5 \mathrm{~mm}$ ) or short $3.25 \mathrm{~mm}$ (extreme from 2 to $3.5 \mathrm{~mm}$ ). The supra-cavernous segment measured on the right $5.2 \mathrm{~mm}$ (extreme from 2 to $8 \mathrm{~mm}$ ) and on the left 4.6 $\mathrm{mm}$ (extreme from 3 to $7 \mathrm{~mm}$ ). The latero-sellar lodge, a complex and narrowed region is crossed by nervous elements each in its meningeal sheath. This deserves an approach by surgical microdissection.

Key words: Oculomotor nerves - meningeal cone - measurement - cadaver - latero-sellar lodge.
\end{abstract}

\section{INTRODUCTION}

The cavernous lodge $(\mathrm{CL})$ is an extradural dural lodge located on both sides of the sella turcica. It is considered as the intracranial extension of the orbital cavities (Akiko, 2005; Belford, 1966; Bol'shakov, 1964). It is crossed by the carotid siphon surrounded by sympathetic fibers and a dense venous plexus, as well as by functionally important cranial nerves, which are the Oculomotor nerves (III, IV and VI) and the first two nerves of division of the trigeminal nerve (V1 and V2).

It is a region that is clearly narrow, but whose content sums up all the motor innervation of the eye under which the internal carotid artery grows (Caramel, 1983; Carpenter, 1983; Cordier, 1953). In this lodge, each nerve is wrapped in its own meningeal sheath that only dissection can individualize.

\section{MATERIAL AND METHODS}

Sixteen latero-sellar lodges of 8 formalized subjects interested the study of cadaveric dissection of the meningeal sheath of the oculomotor nerve. After circumferential craniotomy on an isolated head, the frontal and parietal lobes were removed to expose the latero-sellar region and the small circumference of the cerebellar tent. Exclusion criterion: Children, adults, free from any cerebral tumor pathology, trauma or infection of any origin. Morphometrically we analyzed the different segments of the nerve on the roof of the sinus and in its sheath using vernier calipers. 
The measurement concerned the supracavernous segment taking into account the two anterior and posterior clinoid processes and the situation of the porus (figure 1).

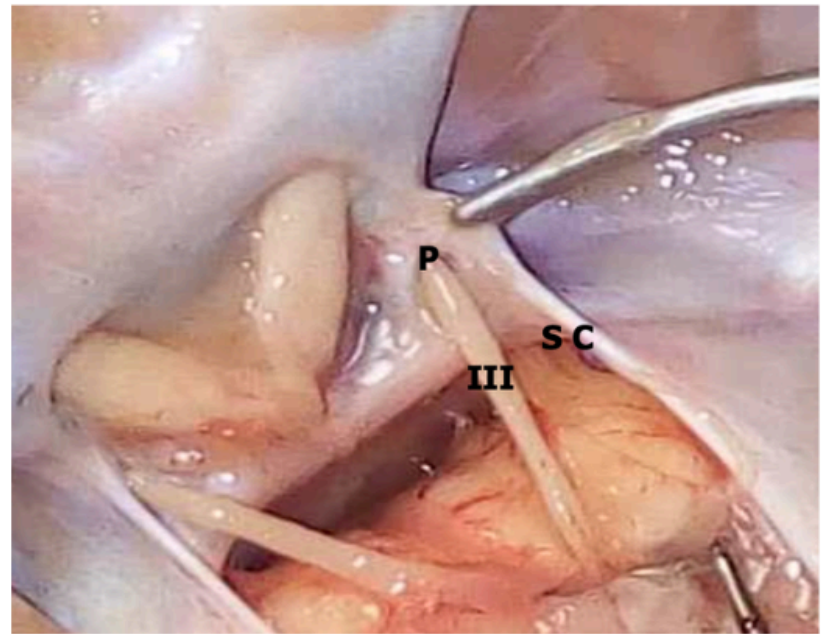

Figure 1a: The porous outside the posterior clinoid process. S C: Small Circumference

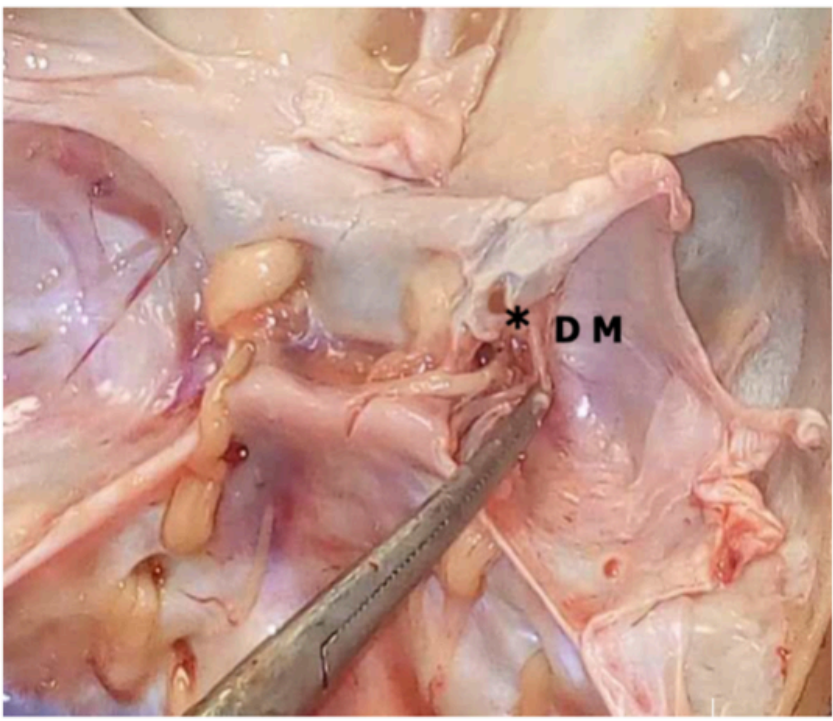

Figure 2: Showing the Measurement of Length of intra conical Segment. D M: Dura Mater. *: arachnoid
Then the intra-conical segment located between the porus and the anterior clinoid process (figure 2). Finally, the anterior preconical or sub-clinoid segment on its lower and lateral face before its entry into the sphenoidal slot (figure 3).

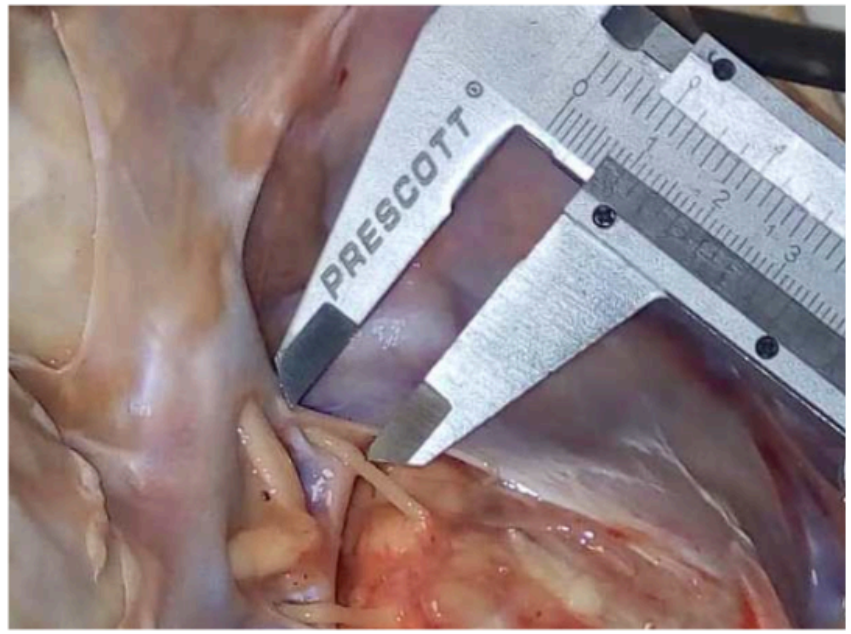

Figure 1b: Showing the Measurement of Length of Supra Cavernous Segment

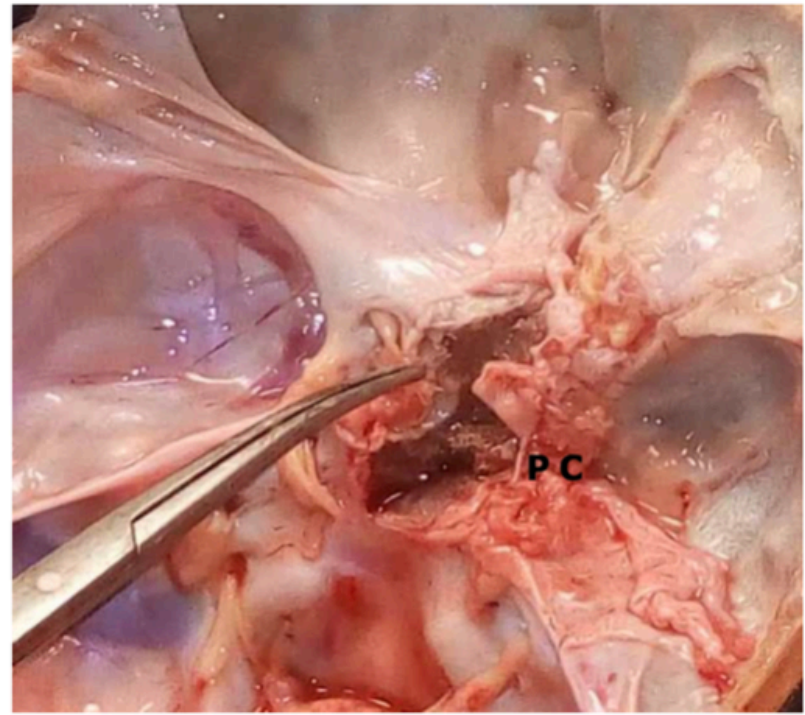

Figure 3: Showing the Measurement of Length of préconical Segment. P C: Pré-Conical 
Anatomy Journal of Africa. 2020. Vol 9 (1): 1713 - 1718.

\section{RESULTS}

We observed three segments of the nerve running through the latero-sellar lodge: The supra-cavernous segment where the nerve was cylindrical, oblique downwards, forwards and outwards. This segment was between the posterior and posterior clinoid process. Its point of penetration or porus was outside the posterior clinoid process.

The entrance orifice of the porus of the oculomotor nerve III was located behind the anterior clinoid process to $7.2 \mathrm{~mm}$ (extreme from 3 to $13 \mathrm{~mm}$ ) on the right and to $7.40 \mathrm{~mm}$ (extreme from 4 to 12) on the left. Two types of nerve penetration were related to the morphology of the cavernous lodge and its roof. The shape was either rhombic $40 \%$ of the study and measured on average $21.37 \mathrm{~mm}$ long (extreme from 18.1 to $20.3 \mathrm{~mm}$ ) and $10.06 \mathrm{~mm}$ wide (extreme from 7.2 to $8.9 \mathrm{~m}$ ) or trapezoidal rectangular $60 \%$ of the study and measured on average $21.37 \mathrm{~mm}$ long (extreme from 50.5 to $28 \mathrm{~mm}$ ) and $10.06 \mathrm{~mm}$ wide (extreme from 9.1 to $18 \mathrm{~mm}$ ).

The nerve was still engaged under the small circumference of the tentorium cerebelli. It was $5.2 \mathrm{~mm}$ from the top of this process. This apparent penetration of the nerve was related to the morphology of the lodge and its roof. The latter was either rhombic with an anterior bank of the porus that is sharp, tapered "in the shape of a point" in contact with the small circumference of the tentorium cerebelli or of rectangular trapezoidal shape where the porus was at mid-distance from both processes. We found two types of porus depending on the anterior bank that was either curvilinear in (U) or sharp in (V). A dural lamella limited the anterior, lateral and anterolateral banks comparable to a sickle oriented backwards and inwards.

The supra-cavernous segment measured on the right $5.2 \mathrm{~mm}$ (extreme from 2 to $8 \mathrm{~mm}$ ) and on the left $4.6 \mathrm{~mm}$ (extreme from 3 to $7 \mathrm{~mm}$ ).
The pre-conical segment was anterior and subclinoid and followed the intra-conical segment. The nerve in its meningeal sheath passed under the lateral part of the lower surface of the process, separated from it by fibrous tissue representing the periosteum and the insertions of the small circumference. The nerve was in close connection with the internal carotid artery, the oculomotor nerve IV and the trigeminal nerve $\mathrm{V} 1$. The total length of the nerve from the porus to the anterior clinoid process was $13.45 \mathrm{~mm}$ (extreme from 8 to $20 \mathrm{~mm}$ ) with no noticeable difference between both sides. Sometimes $13.14 \mathrm{~mm}$ to the right and $13.76 \mathrm{~mm}$ to the left respectively.

The meningeal cone or dural cul-de-sac was constantly found and had a posterior base perpendicular to the apex of the anterior clionoid process. Its top wall was gradually moving away from the roof of the lodge. Its lower wall was in contact with the trochlear nerve IV and the horizontal segment of the internal carotid artery. Its inconspicuous inner wall contrasted with the outer wall made of fibrous lamellae juxtaposed horizontally. The meningeal cul-de-sac represented the intraconical segment and was either $5.2 \mathrm{~mm}$ long (extreme from 4 to $6.5 \mathrm{~mm}$ ) or short $3.25 \mathrm{~mm}$ (extreme from 2 to $3.5 \mathrm{~mm}$ ). Its average length was $4.95 \mathrm{~mm}$ (extreme from 4 to $10 \mathrm{~mm}$ ) with a right and left disparity of $1 \mathrm{~mm}$.

* The intra-conical segment had a horizontal then sagittal nerve that passed under the outer portion of the lower face of the anterior clinoid process and where the highly flexible internal carotid fitted into by its horizontal segment in the super-lateral angle.

* The pre-conical or sub-clinoid segment had an essential relationship with this process. The nerve was still surrounded by its meningeal cone under the process and in the lateral part of its lower face. It was crossed by the trochlear nerve IV attached to the upper edge of the abducens nerve VI. 
Table 1: The summary of the morphometric parameters

\begin{tabular}{|l|l|l|l|l|}
\hline & Rhombic & Mean \pm Sd & Rectangular Trapezoidal & Mean \pm Sd \\
\hline Long $(\mathrm{mm})$ & 21,37 & $18 \pm 2,2$ & 21,37 & $20 \pm 8,5$ \\
\hline Wide $(\mathrm{mm})$ & $7 \pm 1,7$ & $7 \pm 1,7$ & 10,06 & $9 \pm 9,1$ \\
\hline
\end{tabular}

\section{DISCUSSION}

The orifice of penetration of the oculomotor nerve III in the cavernous lodge was described in a variable way according to the authors (De recondo, 2007; Frederickson, 1991; Haines, 1993; Harris, 1976). Some located it, without more precision, at the level of the roof of the lodge (Inoue, 1990; Kehrli, 1997). For the entry of oculomotor nerve III into the cavernous lodge, it is to TAPTAS that we owe the modern conception of the mode of entry of oculomotor nerve III into the roof of the cavernous lodge. For a long time, it had already been noticed that each nerve penetrating into the sinus wall seems to involve a seed, which, widening, isolates it from the neighboring nerves.

Others, more numerous, equidistant between the anterior and posterior clinoid processes (Belford, 1966; Caramel, 1983; Mercier, 1970; Parkinson, 1990) or a little ahead of this median point (patouillard, 1972; Poirier, 1894). Finally, several others located it laterally in relation to the posterior clinoid process (Pernkopf, 1963; Taptas, 1949) or then a little ahead of the latter (Belford, 1966; patouillard, 1972). The vast majority of the authors located the oculomotor nerve in the lateral wall of the cavernous lodge and in a variable manner according to their conception of this lateral wall. If they consider that this wall is split, they placed it either in the superficial lamella, or in the deep lamella, or in both lamellae.

Parkinson located the penetration of oculomotor nerve III into the roof of the cavernous sinus in a fairly classical manner, forward and slightly outside the porus of oculomotor nerve IV, within and below the bank of the free edge of the tent just above the meningo pituitary trunk. The nerve engages in a half-horn with two walls, a lower one formed by the roof of the sinus and a super external one, formed by the small circumference of the tentorium cerebelli, which progressively opens out forward and covers the nerve.

Some authors like (Taptas, 1949; Weninger, 1997) reported the existence of an oblique dural cul-de-sac at the bottom and in front of which the ceiling was discreetly protruding and whose floor, on the contrary, is curved like a gutter. They noted that after notching the roof of the cavernous lodge in front of the posterior clinoid process, the oculomotor nerve III carried with it a meningeal envelope similar to the trigeminal cavity (dura mater; arachnoid).

\begin{tabular}{|l|l|l|l|l|}
\hline & Rhombic & Mean \pm Sd & $\begin{array}{l}\text { Rectangular } \\
\text { Trapezoidal }\end{array}$ & Mean \pm Sd \\
\hline Long $(\mathrm{mm})$ & 21,37 & $18 \pm 2,2$ & 21,37 & $20 \pm 8,5$ \\
\hline Wide $(\mathrm{mm})$ & $7 \pm 1,7$ & $7 \pm 1,7$ & 10,06 & $9 \pm 9,1$ \\
\hline
\end{tabular}


They specified that the meningeal sheaths of nerves III and V1 were rather thick and constantly individualizable whereas that of nerve IV is thinner and sometimes undetectable. They had always found a dural and arachnoidal cul-de-sac, accompanying the oculomotor nerve III during its crossing of the roof until the lateral wall. Most of the authors (Akiko, 2005; Yasuda, 2005) insisted on the close relationship between the oculomotor nerve and the underlying trochlear nerve. They located the oculomotor nerve III in the anterior third of the lateral wall, a nerve that divides into two branches before the superior orbital fissure. The length of this segment, from the bottom of the dural cul-de-sac is $18.9 \mathrm{~mm}$ (extremes of 14 to $23.5 \mathrm{~mm}$ ). They insisted on the relations of the nerve, first with the horizontal segment, then with the second elbow of the carotid siphon. In conclusion, crossroad region of the base of the skull, the cavernous lodge, an extradural space, contains the carotid siphon, its collaterals, the oculomotor nerves and the ophthalmic branch of the trigeminal, as well as a venous plexus.

In conclusion, the complexity of the ratios of these different elements, as well as the small size of the region, explains the difficulty and consequently the rarity of the surgical approach of this lodge. The nerves are located inside the lodge, and their sheaths are united by an easily dissolvable spider membrane. The location and course of these nerves determine the size and shape of Parkinson triangle. The trochlear nerve in particular is the key to the approach of this region.

Acknowledgements: the authors are grateful to the personality from the morgue that gave the cadavers without any economic benefit to Bouaké University Graduate School of Medecine.

\section{REFERENCES}

1. Akiko Y, Noriko S, Ayoko T, Takahito et al. (2005). Normal cranial nerves in the cavernous sinuses: contrast-enhanced three-dimensional constructive interference in the steady state. $\mathrm{Mr}$ imaging Am. Neuroradiol, 26: 946-950.

2. Belford M. The "cavernous" sinus BRIT.1966. N ophtalm. 50: 41-46

3. Bol'shakov OP.1964. Macroscopical and microscopic structural features of cavernous sinus. Fed proc, 23: 308- 311.

4. Caramel J.P. Bonnel. 1983. The oculomotor nerve: biometry and endoneural fascicular systhematisation. Ant. Clim, 5: 159- 168.

5. Carpenter MB suttin J. 1983. Human neuroanatomy eighth Ed. Baltimore- Williams and Wikins.

6. Cordier J. cayotte j. 1953. Le nerf moteur oculaire commun. Leçon anat. phusiol Ophtalm. monaco - Dulcis.

7. De recondo J, Guelguen B. 2007. Anatomie des nerfs oculo-moteurs. Encly. med. Chir, A 104.10.11.

8. Frederickson RG. 1991. The subdural space interpreted as a cellular layer of meninges. Anat rec, 230: 38- 51.

9. Haines $\mathrm{DE}$, Harkey $\mathrm{HL}$, al-mefty O. 1993. The subdural space: a new look at an outdated concept. Neurosurgery, 32: 111-120.

10. Harris FS, Rhoton. 1976. Anatomy of the cavernous sinus. A microsurgical study. J. neurosurg, 45: $169-180$

11. Inoue $T$, Rhoton $A L$, Theele D. 1990. Surgical approaches to the cavernous sinus: a microscurgical study. Neurosurgery, 26: 903-932. 
12. Kehrli P, Ali MM, Maillot C, et ai. 1997. Comparative microanatomy of the lateral wall of the cavernous sinus in humans and the olive baboon. Neurol Res, $19: 571-576$.

13. Mercier RP, patouillard C, vanneuville G. 1970. Study of cavernous sinus by the simultaneous use serval search methods CR assoc. anat, 149: 877- 890.

14. Parkinson D. 1990. Surgical anatomy of lateral sellar compartment (cavernous sinus) clin neurosurg, 36: 219-239.

15. Patouillard P, vanneuville G. 1972. The wails of the cavernous sinus. Neurochirugie, 18 : $551-$ 560.

16. Poirier P. 1894. Traité d'anatomie humaine paris masson, vol 3 : 97- 104.

17. Pernkop F, Ferner H. 1963. Atlas of topographic and applied human anatomy philadelphia: WB saunders. 1: 73- 75.

18. Taptas JN. 1949. la loge du sinus caverneux, sa constitution et les rapports des éléments vasculaires et nerveux qui la traversent. Sem hôp, 25: 1719-1722.

19. Weninger WJ, Streicher J and J müller GB .1997. Anatomical compartment of the parasellar region; adipose tissue bidies represent intracranial continuations of extracranial spaces. J Anat, 191 : $269-257$.

20. Yasuda A, Campero A, Martins C, Rhoton AL, de Oliviera E. 2005. Microsurgical anatomy and approaches to the cavernous sinus. Neurosurgery. 56: 4-27. 